\title{
A 30-Year Single-center Experience of Cementless Total Hip Arthroplasty With Spongy Metal Structured Implants: A Follow-up of a Previous Report
}

\author{
FLORIAN LENZE ${ }^{1}$, CHRISTIAN SCHEELE ${ }^{1}$, PHILIPP KÖSTERS ${ }^{1}$, LUDGER GERDESMEYER $^{2}$, \\ IGOR LASIC $^{1}$, FLORIAN POHLIG ${ }^{1}$, HEINRICH MÜHLHOFER ${ }^{1}$, ULRICH LENZE ${ }^{1}$, \\ RÜDIGER VON EISENHART-ROTHE ${ }^{1}$ and NORBERT HARRASSER ${ }^{1}$ \\ ${ }^{1}$ Department of Orthopedics and Sports Orthopedics, Klinikum rechts der Isar, \\ Technical University Munich, Munich, Germany; \\ ${ }^{2}$ Department of Orthopedics and Trauma Surgery, University Medical Centre Schleswig Holstein, Kiel, Germany
}

\begin{abstract}
Background/Aim: The aim of this study was to analyze survivorship and functional outcome of cementless spongy metal structured total hip arthroplasty (THA) after ultra-long-term follow-up. Patients and Methods: A total of 100 THAs in patients under 65 years at initial surgery were performed between 1985 and 1989 at our Department. Twenty patients (23 hips) were available for final follow-up. Implant survivorship and functional results (Merle d'Aubigné, SF-12) were assessed. Results: At a mean follow-up of 30 years (range $=27.7-31.7$ years), the overall stem survival rate was $82.6 \%$ (19/23 stems) and the overall cup survival rate was $52.2 \%$ (12/23 cups). Revision surgeries were performed for aseptic loosening in all cases. Functional evaluation revealed good to excellent results in 16 patients (80\%) Conclusion: Spongy metal structured cementless THA provides remarkable survivorship and excellent functional results even after ultralong-term follow-up. Further research regarding modern implants, bearing surfaces etc. is required to assess survivorship and clinical outcomes of different implant designs.
\end{abstract}

Total hip arthroplasty (THA) is often considered one of the most successful orthopedic procedures for patients suffering from end-stage osteoarthritis of the hip (1). Cementless fixation of both stem and cup is applied in $86 \%$ of THA in the U.S. and in $77 \%$ of primary THA in Germany $(2,3)$. This procedure was

This article is freely accessible online.

Correspondence to: Florian Lenze, MD, Department of Orthopedics and Sports Orthopedics, Klinikum rechts der Isar, Technical University Munich, Ismaninger Str. 22, 81675 Munich, Germany. E-mail: Flo_Lenze@yahoo.de

Key Words: Total hip arthroplasty, cementless, spongy metal structured, young patients. initially designed for young, active patients with high bone quality (4). Various studies report encouraging results for this patient group (5-8). Petsatodes et al. reported a survivorship of 98\% after 17 years based on the analysis of 195 patients (205 hips) who received a fully porous-coated stem (7). Ellison $e t$ al. reported a femoral survivorship of $99.2 \%$ after 15 years based on the analysis of 249 proximally coated stems in 201 patients (8), and a meta-analysis performed by Springer et al. reported a femoral survivorship of $95 \%$ at 12 years in patients younger than 60 years at implantation (9). However, the National Joint Registry of England and Wales shows substantially higher long-term revision rates for uncemented stems than for cemented stems (10).

The existing variability in the survivorship of cementless THA is largely attributable to specific design features (11). The geometry and surface texture of implants are two of the most important factors for long-term fixation and stability. Surface structures similar to cancellous bone support bony anchorage with direct bone contact to provide long-term stability. Meso-structure surfaces with a pore size of 100$2,000 \mu \mathrm{m}$ and a porosity larger than $40 \%$ can replicates surface structures similar to cancellous bone morphology and optimize osseus integration $(12,13)$.

A former report of the presented patient group which was treated with first-generation spongy metal structured implants showed an overall survival rate of $93.7 \%$ at a mean follow-up of 19 years (14). The purpose of this study was to update the results of a prospective series of primary cementless THAs after a mean follow-up period of 30 years.

\section{Patients and Methods}

The study protocol was approved by the Medical Ethical Committee at the Klinikum rechts der Isar (Technical University of Munich) and registered as a clinical trial (NCT number: NCT03045536).

Between February 1985 and February 1989, a total of 100 consecutive cementless primary THAs in 88 patients were 
implanted via a posterior approach. The results of the 19-year follow-up period have already been published elsewhere (14). The patients who were included in the previous study were invited again to participate in this ultra-long-term follow-up study. The indications for primary THA are listed in Table I. The mean age of the patients at time of initial surgery was 47.5 years (18-65 years; female to male $=49: 51$ out of 100 THAs); 49 THAs were implanted on the right side.

In all cases, a side-specific anatomical double-curved stem and a hemispherical cup, with fully porous metal surface (stem-type GHE; ESKA/AQ Implants, Lübeck, Schleswig-Holstein, Germany) was used. The spongy metal structured surface, with a porosity of $60 \%$ and a pore size from 800 to $1,500 \mu \mathrm{m}$, resembles cancellous bone. Two spikes and a peg wedged into the acetabular rim and the ischium support the primary stability of the acetabular cup. The femoral and acetabular component were manufactured of an alloy of chrome, cobalt and molybdenum. The metal backed articular surface was made of standard polyethylene and ceramic heads with a diameter of $28 \mathrm{~mm}$ were used in all cases.

Postoperatively, weight bearing was limited for 6 weeks and physiotherapy was conducted for 3 months in order to improve muscle strength and mobilization of the hip. Patients were routinely followed-up 6-8 weeks postoperatively and then at different followup appointments depending on the distance to our clinic. On average, four follow-up appointments at a mean of 0.6 years, 3.4 years, 17 years and 29.9 years after the initial operation were kept; 68 patients ( 80 hips) were lost at the last follow-up.

With regard to survivorship, the end-point was defined as revision for any reason. Functional results were evaluated using the Merle d'Aubigné rating system and MacNab's outcome assessment of patient satisfaction $(15,16)$. Additionally, global outcome including mental and physical health was measured via the SF-12 short form questionnaire and postoperative pain was scored on the 10 -point visual analog scale (VAS) $(17,18)$.

Statistical analysis. Statistical evaluation and analysis were performed using SPSS 21.0 software (IBM SPSS, Armonk, NY, USA). Survivorship analysis (Kaplan-Meier curves) was carried out with revision for any reason as the end-point. Statistical analysis of Merle d'Aubigné score and SF-12 was carried out using the paired $t$-test (significance level: 0.05 ).

\section{Results}

At a mean follow-up time of 29.9 years (range=27.7-31.7 years), 20 out of 88 patients and 23 out of 100 THAs were available for evaluation (follow-up rate of $23 \%$ ). One patient refused to participate in the study and 67 patients were lost to follow-up (23 patients with unknown/changed address; 44 patients had died). The remaining patients, seven males and 16 females, had a mean age \pm SD of 77.2 \pm 7.65 years (range $=56-89$ years) and a mean body mass index (BMI) of $25.14 .29 \mathrm{~kg} / \mathrm{m}^{2}$ (range $=18.8-35.4 \mathrm{~kg} / \mathrm{m}^{2}$ ). There was no correlation between age or BMI and revision rate for any component $(p=0.87)$.

The stem survival rate at the last follow-up was $82.6 \%$ (19123 stems) (Figure 1). Revision of the stem was performed in four out of the 23 observed cases, on average after 17.1 \pm 6.32 years (range=10.6-25.4 years) for aseptic
Table I. Indications for primary total hip arthroplasty of the study cohort with full follow-up.

\begin{tabular}{lc}
\hline Diagnosis & Number of patients $(\%)$ \\
\hline Hip dysplasia & $9(39.1 \%)$ \\
Post-traumatic avascular necrosis & $4(17.4 \%)$ \\
Epiphyseal varus deformity & $4(17.4 \%)$ \\
Perthes disease & $3(12.0 \%)$ \\
Idiopathic avascular necrosis & $2(8.7 \%)$ \\
Rheumatoid arthritis & $1(4.3 \%)$ \\
Total & $23(100 \%)$ \\
\hline
\end{tabular}

Table II. Mean Merle d'Aubigné hip scores (max. 6 points for each category).

\begin{tabular}{lcc}
\hline Measure & Preoperatively & Postoperatively* \\
\hline Pain & $2.69 \pm 0.77$ & $5.42 \pm 1.07$ \\
Mobility & $3.59 \pm 1.23$ & $4.59 \pm 1.53$ \\
Ability to walk & $3.19 \pm 0.94$ & $3.58 \pm 2.06$ \\
\hline
\end{tabular}

*At a mean of 29.7 years.

loosening. Eleven out of the 23 acetabular components underwent revision (all for aseptic loosening). Therefore, the overall acetabular survival rate was $52.2 \%$ at final follow-up (Figure 2). The mean time to cup revision was 15.8 \pm 6.18 years (range $=5.4-26$ years). No correlation between the revision rate and $\mathrm{BMI}$, age or gender was identified.

Concerning the functional results at the last follow-up, the Merle D'Aubigné score showed an overall mean improvement of 7.24 points compared to the preoperative situation. The scores for all three subsets (pain, mobility and ability to walk) were superior to those of the preoperative state (Table II). The largest improvement was found with regard to pain, with a long-term improvement of $2.72 \pm 1.07$ points. The ability to walk remained $0.39 \pm 2.06$ points above the preoperative value and mobility was improved by $1.00 \pm 1.53$ point (Figure 3 ). The average total score was $13.6 \pm 3.30$ out of 18 points. Four patients rated 18.0 points, more than $50 \%$ of the patients rated 15.0 points or more and no patient rated below 9.0 points. Compared to the 19 -year follow-up, no significant changes had occurred.

The evaluation of SF-12 questionnaires revealed a mean physical sum score of $36.4 \pm 10.02$ points and a mean mental score of $59.7 \pm 4.36$ points. Thus, with respect to the mean physical sum score, the patients were less healthy compared to a general German population (mean=54). The differences in SF-12 scores between patients with revision and without revision were not statistically significant. Compared to the 19-year follow-up, no significant changes had occurred. 


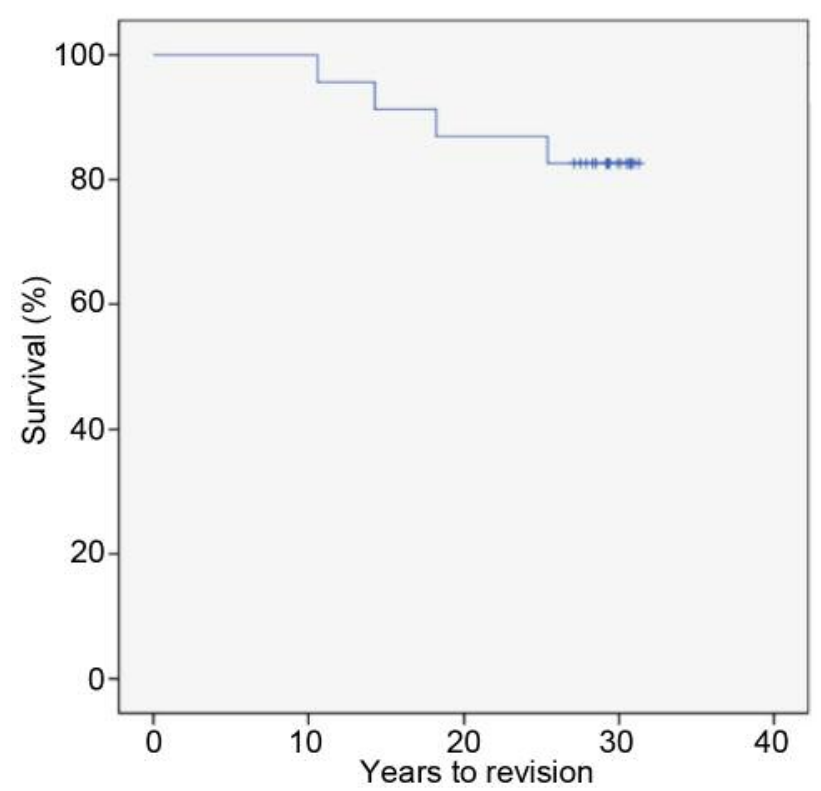

Figure 1. Kaplan-Meier survival curve of time to stem revision for any reason, with a survival of $82.6 \%$ (19/23 stems) after 30 years of follow-up.

Concerning the MacNab score, four patients (21.1\%) reported an excellent, $12(63.2 \%)$ a good and three (15.8\%) a fair level of well-being at final follow-up. No patient stated a poor outcome and there was no correlation between revision surgery and the MacNab score. Fifteen patients stated they would recommend the procedure to a friend, even 30 years after surgery.

Thirteen patients $(68.4 \%)$ reported no pain at the last follow-up, four patients $(21.1 \%)$ reported light pain (VAS 13 ) and two (10.5\%) reported moderate pain (VAS 6-7). No patient reported sever pain (VAS 8-10).

\section{Discussion}

The aim of the present study was to provide ultra long-term results after cementless THA with first-generation spongy metal structured implants in patients younger than 65 years at initial operation. We prospectively enrolled 88 patients (100 hips) who underwent THA at an orthopaedic university clinic and assessed implant survival rates (revision for any reason) and functional outcome. At a mean follow-up of 30 years, 20 patients ( 23 hips) with a mean age of 77 years were available for evaluation. The stem survival rate at the last follow-up was $82.6 \%$ (19/23 stems) whereas acetabular survival rate was $52 \%$ (12/23 cups). Concerning functional results, improvement from the preoperative situation was still apparent even after 30 years. To the best of our knowledge, this is the first single-center study reporting on ultra long-

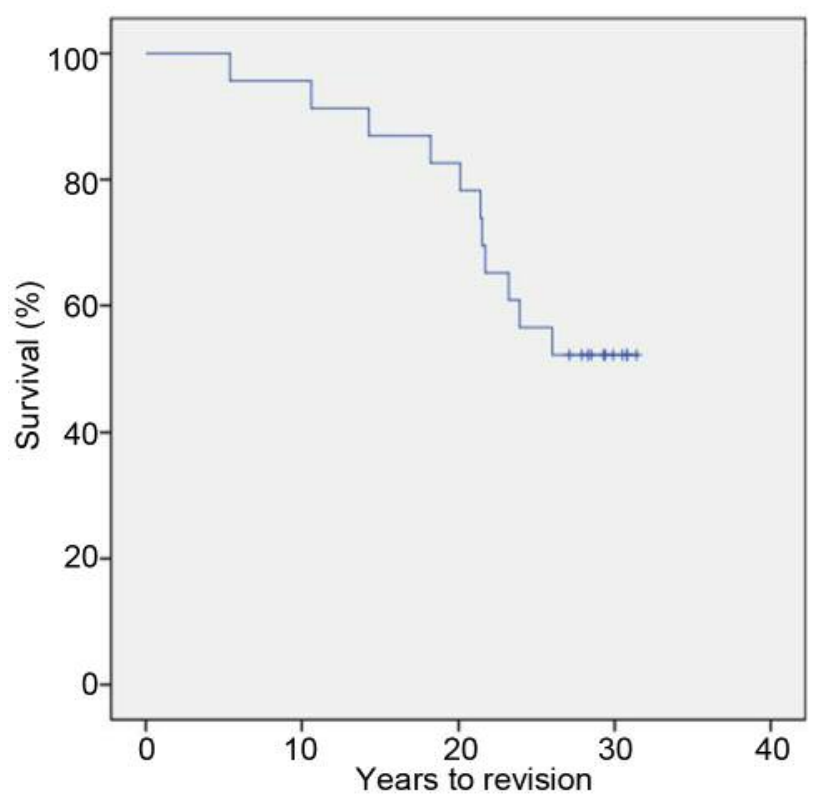

Figure 2. Kaplan-Meier survival curve of time to socket revision for any reason, with a survival of $52.2 \%$ (12/23 cups) after 30 years of follow-up.

term results for THA with a cementless spongy metal structured device initially implanted in patients younger than 65 years.

Generally, hip replacement in young patients remains a challenge as younger patients are considered to be more active and therefore expose the implant to significantly higher loads leading to increased rates of early implant failure. Results of cemented THA revealed excellent longterm results with a survivorship of more than $80 \%$ at 20 years after surgery (19). However, young age at the time of implantation was identified as a negative predictor for early aseptic loosening and consequent implant failure. For example, Berry et al. in a 25-year follow-up study of 2,000 hip arthroplasties found that the survivorship rate was $68.7 \%$ in patients younger than 40 years compared to $100 \%$ in patients aged 80 years and older (20). Despite these excellent results for cemented THA, cementless fixation is now commonly used in younger patients. However, data supporting the use of cementless, instead of cemented fixation in these patients are lacking, especially if potential problems of cementless THA including femoral fractures, aseptic loosening and thigh pain are considered $(21,22)$. Our observations in the present study support the use of cementless fixation in young patients.

The first outcomes of cementless femoral fixation were reported in the late 1970s $(23,24)$. Although there has been a substantial technical evolution of design principles and surface structure, stem geometry and metallurgic aspects, 


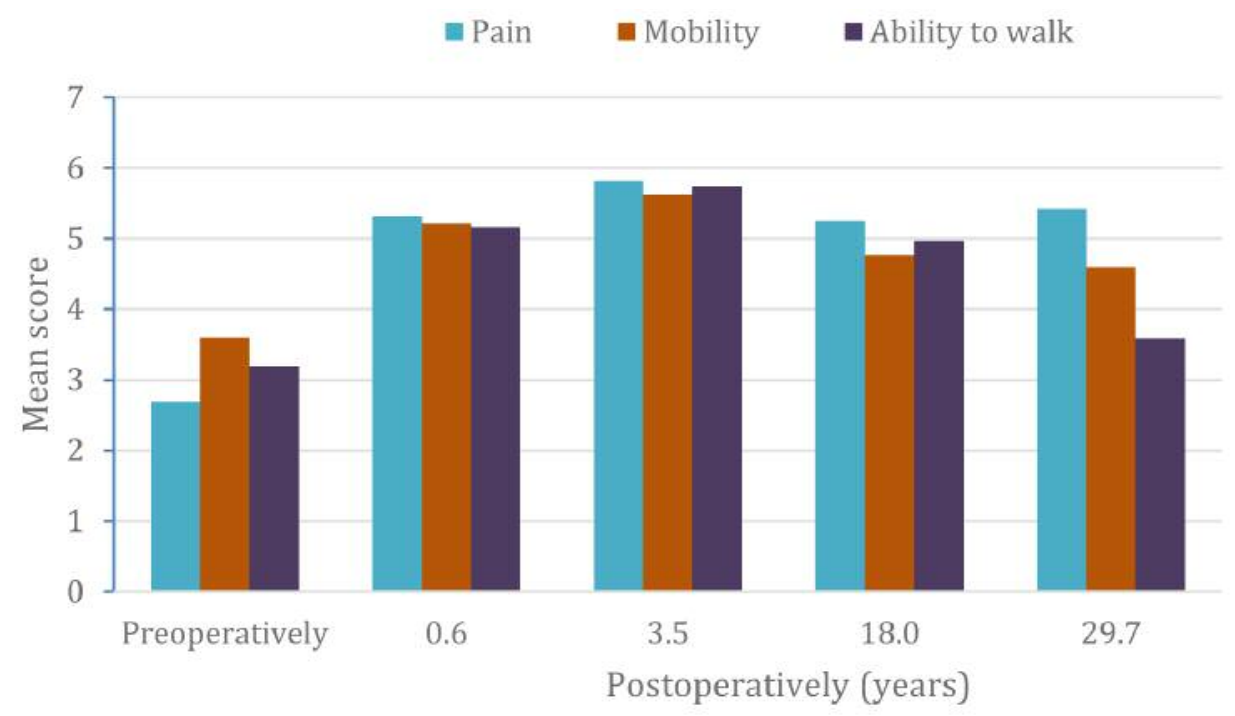

Figure 3. Development of the Merle d'Aubigné hip score by sub-measure over the follow-up period.

there has been consistent concern with regard to long-term durability of the femoral component in non-cemented THA in young patients. In order to provide long-term stability, the biological fixation of the implant by bone ingrowth is essential. The structured porous surface of the presented spongy metal system achieves bony ingrowth by providing an open three-dimensional network with high interconnectivity (porosity of $60 \%$ ) and excellent structural compatibility (14). In general, successful bone ingrowth requires pore sizes between 100 and 2,000 $\mu \mathrm{m}$ and a percentage of voids of up to $40 \%$ in order to optimize mechanical strength $(12,13)$. Several former studies found good to excellent shor- and mid-term results when spongy metal structured implants were used. For example, Sugano et al. reported on 59 patients (66 hips) younger than 65 years at initial surgery who were prospectively followed-up for 2 to 6 years (25). The clinical outcome of all hips was rated as either excellent or good and no patient needed revision surgery during the observation period. Similar mid-term results were published by Matsui et al. in 1998 (26). In all of the 45 patients (49 hips) excellent or good results for the Merle D'Aubigné score after 5 to 9 years were found. Only two patients had to undergo revision because of neck fracture or infection, and three reported thigh pain which had resolved within 2 years after surgery. In a previous report (based on the same patient group), we confirmed excellent mid-term results in a long-term survival analysis of 84 patients (93 hips) (14). At 19-year follow-up, the overall stem survival rate was $93.7 \%$ and the overall cup survival rate was $82.3 \%$. Clinical outcome scores revealed good to excellent results of the implanted THAs in $87 \%$ of patients. In the present study, we were able to update these results.
Overall GHE stem survival was $82.6 \%$ and the overall cup survival rate was $52.2 \%$ in our cohort. In the literature, femoral components generally outperform their acetabular counterparts in terms of survival rates; furthermore, survivorship of the acetabular component is more affected by age than is the femoral stem $(20,27)$. Despite the ultralong observation period, functional investigation revealed that more than $80 \%$ of patients reported either excellent or good levels of well-being. Evaluation of the SF-12 (physical sum score) revealed patients were less healthy compared to a general German population. Interestingly, with respect to the mental sum score, our cohort had high normal values.

Our study has certain important limitations. Due to the long observation period, there was a substantial drop-out of patients. Nevertheless, we believe the cohort is still representative enough to provide important findings on survival rates of the investigated THA design. Another limitation is the fact that we assessed only one specific implant without any control group. Therefore, we cannot assume that other designs would have performed less well. Furthermore, the scores we used are not sensitive enough to give specific information about characteristic problems of certain THAs, e.g. thigh pain.

\section{Conclusion}

Our results indicate that cementless spongy metal implants in primary THA provide reliable survivorship and excellent functional results in patients younger than 65 years at initial operation even after an ultra-long follow-up. However, the excellent overall outcome of spongy metal stems substantially outperforms the survival rates of their acetabular counterparts. 
Further research is required to assess clinical outcomes of more recent implant designs, reflecting the technical evolution of geometries and surface textures.

\section{Ethics Approval and Consent to Participate}

This study was approved by the local Ethics Committee. All enrolled patients gave their informed consent to participate in this study.

\section{Conflicts of Interest}

The Authors declare there were no conflicts of interest in regard to this study.

\section{Authors' Contributions}

$\mathrm{NH}$ was responsible for ethics approval, data analysis/interpretation and article preparation. NH, FL, RER, HM, IL were involved in the initial study idea, data interpretation and article preparation. PK conducted the data collection, follow-up visits and preliminary data analysis. FP was involved in the process of ethics approval, data collection and interpretation. UL was one of the study instigators, was involved in data interpretation and in article preparation. LG had the idea for the study, outlined the ethics proposal, conducted final data analysis and interpretation and was responsible for the final article. All Authors have read and approved the final version of the article.

\section{Acknowledgements}

This study was supported by the Wilhelm-Sander Foundation (project number: 2009.905.2), which is a charitable, non-profit foundation for promotion of cancer research.

\section{References}

1 Callaghan JJ, Albright JC, Goetz DD, Olejniczak JP and Johnston RC: Charnley total hip arthroplasty with cement. Minimum twenty-five-year follow-up. J Bone Joint Surg Am 82(4): 487-497, 2000. PMID: 10761939.

2 Dunbar MJ: Cemented femoral fixation: The north atlantic divide. Orthopedics 32(9), 2009. PMID: 19751019. DOI: 10.3928/01477447-20090728-07

3 Steinbrück AGVJTLOMA: Annual report endoprothesenregister deutschland (eprd). EPRD Deutsche Endoprothesenregister $\mathrm{gGmbH}, 2018$.

4 Dorr LD, Absatz M, Gruen TA, Saberi MT and Doerzbacher JF: Anatomic porous replacement hip arthroplasty: First 100 consecutive cases. Semin Arthroplasty 1(1): 77-86, 1990. PMID: 10149561 .

5 Aldinger PR, Thomsen M, Mau H, Ewerbeck V and Breusch SJ: Cementless spotorno tapered titanium stems: Excellent 10-15year survival in 141 young patients. Acta Orthop Scand 74(3): 253-258, 2003. PMID: 12899543. DOI: 10.1080/000164703 10014157

6 Eskelinen A, Remes V, Helenius I, Pulkkinen P, Nevalainen J and Paavolainen P: Uncemented total hip arthroplasty for primary osteoarthritis in young patients: A mid-to long-term follow-up study from the finnish arthroplasty register. Acta Orthop 77(1): 57-70, 2006. PMID: 16534703. DOI: 10.1080/ 17453670610045704

7 Petsatodes GE, Christoforides JE, Papadopoulos PP, Christodoulou AG, Karataglis D and Pournaras JD: Primary total-hip arthroplasty with the autophor 900 -s fully porous coated stem in young patients seven to seventeen years of follow-up. J Arthroplasty 20(4): 436-442, 2005. PMID: 16124958. DOI: 10.1016/j.arth.2004.09.048

8 Ellison B, Berend KR, Lombardi AV, Jr. and Mallory TH: Tapered titanium porous plasma-sprayed femoral component in patients aged 40 years and younger. J Arthroplasty 21(6 Suppl 2): 32-37, 2006. PMID: 16950059. DOI: 10.1016/j.arth. 2006.03.008

9 Springer BD, Connelly SE, Odum SM, Fehring TK, Griffin WL, Mason JB and Masonis JL: Cementless femoral components in young patients: Review and meta-analysis of total hip arthroplasty and hip resurfacing. J Arthroplasty 24(6 Suppl): 28, 2009. PMID: 19556097. DOI: 10.1016/j.arth.2009.04.032

10 Hughes RE, Batra A and Hallstrom BR: Arthroplasty registries around the world: Valuable sources of hip implant revision risk data. Curr Rev Musculoskelet Med 10(2): 240-252, 2017. PMID: 28337731. DOI: 10.1007/s12178-017-9408-5

11 Khanuja HS, Vakil JJ, Goddard MS and Mont MA: Cementless femoral fixation in total hip arthroplasty. J Bone Joint Surg Am 93(5): 500-509, 2011. PMID: 21368083. DOI: 10.2106/ JBJS.J.00774

12 Bobyn JD, Pilliar RM, Cameron HU, Weatherly GC and Kent GM: The effect of porous surface configuration on the tensile strength of fixation of implants by bone ingrowth. Clin Orthop Relat Res 149: 291-298, 1980. PMID: 7408314.

13 Mittelmeier W, Grunwald I, Schafer R, Grundei H and Gradinger R: Cementless fixation of the endoprosthesis using trabecular, 3-dimensional interconnected surface structures. Orthopade 26(2): 117-124, 1997. PMID: 9157350.

14 Gerdesmeyer L, Al Muderis M, Gollwitzer H, Harrasser N, Stukenberg M, Clifford MA and Toepfer A: 19 years outcome after cementless total hip arthroplasty with spongy metal structured implants in patients younger than 65 years. BMC Musculoskelet Disord 17(1): 429, 2016. PMID: 27756273. DOI: 10.1186/s12891-016-1285-3

15 Macnab I: Negative disc exploration. An analysis of the causes of nerve-root involvement in sixty-eight patients. J Bone Joint Surg Am 53(5): 891-903, 1971. PMID: 4326746.

16 D'Aubigne RM and Postel M: Functional results of hip arthroplasty with acrylic prosthesis. J Bone Joint Surg Am 36A(3): 451-475, 1954. PMID: 13163078.

17 Williamson A and Hoggart B: Pain: A review of three commonly used pain rating scales. J Clin Nurs 14(7): 798-804, 2005. PMID: 16000093. DOI: 10.1111/j.1365-2702.2005.01121.x

18 Ware J Jr., Kosinski M and Keller SD: A 12-item short-form health survey: Construction of scales and preliminary tests of reliability and validity. Med Care 34(3): 220-233, 1996. PMID: 8628042.

19 Kavanagh BF, Wallrichs S, Dewitz M, Berry D, Currier B, Ilstrup D and Coventry MB: Charnley low-friction arthroplasty of the hip. Twenty-year results with cement. J Arthroplasty 9(3): 229-234, 1994. PMID: 8077970.

20 Berry DJ, Harmsen WS, Cabanela ME and Morrey BF: Twentyfive-year survivorship of two thousand consecutive primary 
charnley total hip replacements: Factors affecting survivorship of acetabular and femoral components. J Bone Joint Surg Am 84-A(2): 171-177, 2002. PMID: 11861721.

21 Barrack RL, Jasty M, Bragdon C, Haire T and Harris WH: Thigh pain despite bone ingrowth into uncemented femoral stems. J Bone Joint Surg Br 74(4): 507-510, 1992. PMID: 1624506.

22 Engh CA and Bobyn JD: The influence of stem size and extent of porous coating on femoral bone resorption after primary cementless hip arthroplasty. Clin Orthop Relat Res 231: 7-28, 1988. PMID: 3370887.

23 Judet R, Siguier M, Brumpt B and Judet T: A noncemented total hip prosthesis. Clin Orthop Relat Res 137: 76-84, 1978. PMID: 743847.

24 Lord GA, Hardy JR and Kummer FJ: An uncemented total hip replacement: Experimental study and review of 300 madreporique arthroplasties. Clin Orthop Relat Res 141: 2-16, 1979. PMID: 477107.
25 Sugano N, Saito S, Takaoka K, Ohzono K, Masuhara K, Saito $\mathrm{M}$ and Ono K: Spongy metal lubeck hip prostheses for osteoarthritis secondary to hip dysplasia. A 2-6-year follow-up study. J Arthroplasty 9(3): 253-262, 1994. PMID: 8077973.

26 Matsui M, Nakata K, Masuhara K, Ohzono K, Sugano N and Ochi T: The metal-cancellous cementless lubeck total hip arthroplasty. Five-to-nine-year results. J Bone Joint Surg Br 80(3): 404-410, 1998. PMID: 9619926.

27 Streit MR, Schroder K, Korber M, Merle C, Gotterbarm T, Ewerbeck V and Aldinger PR: High survival in young patients using a second generation uncemented total hip replacement. Int Orthop 36(6): 1129-1136, 2012. PMID: 22113735. DOI: $10.1007 / \mathrm{s} 00264-011-1399-\mathrm{z}$

Received February 5, 2019

Revised March 13, 2019

Accepted March 15, 2019 